\title{
Clinico-histopahological patterns of benign gynecological lesions at a tertiary hospital in Eastern Nigeria: a 5 year review
}

\author{
Uzoma O. I.*, Ejikem E. C.
}

Department of Obstetrics and Gynecology, Imo State University, Nigeria

Received: 22 April 2017

Accepted: 18 May 2017

\section{*Correspondence:}

Dr. Uzoma O. I.,

E-mail: drbiggie2001@gmail.com

Copyright: (C) the author(s), publisher and licensee Medip Academy. This is an open-access article distributed under the terms of the Creative Commons Attribution Non-Commercial License, which permits unrestricted non-commercial use, distribution, and reproduction in any medium, provided the original work is properly cited.

\begin{abstract}
Background: Gynecological lesions are a common reason for women to seek specialist care. Even benign lesions manifest with a wide variety of clinical features. This study set out to analyze the prevalence of histopathologically evaluated benign lesions of the genital tract and their diverse clinical presentations within a tertiary healthcare institution.

Methods: This was a retrospective study of 265 cases of gynecological specimens sent for histopathology at department of morbid anatomy, relevant clinical data on each case was retrieved from patient case notes obtained from the medical records department of the Imo State University Teaching Hospital Orlu, all data were retrieved from these departments from the period of 1st January 2009 to 31st December 2013. Data was analyzed using SPSS version 20.

Results: A total of 265 specimens $(100 \%)$ were received during a 5 year period. The benign lesions seen included; uterine leiomyomas 120 cases $(45.3 \%)$, cervicitis had $32(12.1 \%)$, there were 22 cases $(8.3 \%)$ of uterovaginal prolapse, product of conception had $20(7.6 \%)$, cervical polyps and cysts had 11cases (4.2\%), adenomyosis and endometriosis had 4 cases $(1.5 \%)$, serous cystadenoma reported 9 cases (3.4\%). Cystic teratoma and simple ovarian cyst had 8 cases $(3.0 \%)$ each. Endometrial hyperplasia, ovarian thecoma and corpus luteum cyst all had 7 cases $(2.6 \%)$ respectively. There were 3 cases $(1.1 \%)$ each of Nabothian cyst and ectopic pregnancy. Fibromas accounted for 2 cases $(0.6 \%)$. Bartholin's cyst and hydrosalpinx had 1 case $(0.4 \%)$ each.
\end{abstract}

Conclusions: Uterine fibroids were the commonest benign lesion for which women underwent gynecological surgery.

Keywords: Cervicitis, Endometriosis, Gynecological, Leiomyoma, Teratoma

\section{INTRODUCTION}

Gynecological lesions have a wide range of clinical features and are a source of physical and/or psychological distress to affected women with socioeconomic implications for the larger society. ${ }^{1}$ Many benign gynecological lesions are associated with significant morbidity; endometriosis producing chronic pelvic pain and infertility is just one example..$^{2,3}$ In these cases need for a thorough history, physical examination and laboratory evaluation cannot be overemphasized; given the fact that certain conditions will have atypical presentation. ${ }^{4}$ The clinical features of each disorder are made clearer with a concise history and a comprehensive physical examination. ${ }^{5}$ This enables the clinician decide on the relevant investigations to undertake; this is crucial especially in resource constrained settings coupled with the burden of HIV/AIDS in sub-Saharan Africa. ${ }^{6}$

However due to the fact that accurate diagnoses is the cornerstone of proper disease management, the need for 
histopathological analysis of post-operative specimens is thus essential. ${ }^{7}$

Pathology is both a medical specialty and an investigative scientific discipline, concerned with understanding the essential nature of human disease; anatomic pathology has a unique place in the practice of evidence based medicine. ${ }^{8}$ Histopathology not only assists in diagnoses and deciding on treatment options but it also helps in the understanding of prevalence, mean age of affectation as well as factoring in the potential impact on fertility for females of reproductive age. ${ }^{9}$

The purpose of the study was to add to the existing database on the clinico-histopathological patterns of gynecological benign diseases.

\section{METHODS}

The study was done at the Imo State University Teaching Hospital, Orlu in Southeastern Nigeria. This was a retrospective study of 265 cases of benign gynecological specimens sent for histopathology at department of morbid anatomy between the timeframe of 1st January 2009 to 31st December 2013, in addition clinical data from the relevant case notes were obtained from the medical records department.

\section{Statistical analysis}

All the data were analyzed on SPSS version 20. The frequency, mean age and educational level of those with various benign disorders were determined.

\section{RESULTS}

Uterine fibroids accounted for a total of 120 cases $(45.3 \%)$; this is captured in Table 1 . The mean age of those with fibroids was 35.7 years SD 9.9. Cervicitis accounted for 32 cases $(12.1 \%)$. Twenty two cases of uterovaginal prolapse were seen in mainly postmenopausal females with a mean age of 59.2 years SD 6.4. They were all multiparous with a parity of more the 4 in $80 \%$ of these cases. Those with uterovaginal prolapsed had a mean age of 59.2 years SD 6.4. A total of 20 cases of abortion with retained products of conception were seen on histopathology. Induced abortions accounted for 6 cases out of a total of 20 cases $(7.6 \%)$ of abortion. Adenomyosis and endometriosis accounted for a total of 4 cases. Ectopic gestations accounted for 3 cases seen. A total of 11 cases of cervical cysts and polyps were seen, the mean age here was 30.8 years SD 9.8, whereas the mean age for cases of serous cystadenoma was 44.1 years SD 10.8. Cystic teratoma and simple ovarian cyst had 8 cases (3.0\%) each. Endometrial hyperplasia, ovarian thecoma and corpus luteum cyst all had 7 cases $(2.6 \%)$ respectively. There were 3 cases $(1.1 \%)$ each of Nabothian cyst and ectopic pregnancy. Fibromas accounted for 2 cases $(0.6 \%)$.
Bartholin's cyst and hydrosalpinx had 1 case $(0.4 \%)$ each.

Since there were 2 stillbirths, and one baby died in immediate neonatal period, analysis for neonatal nursery admission is done in 107 babies. There was a total of 39 babies of $107(36.4 \%)$ who required nursery admission for observation either due to respiratory complications, metabolic complications or sepsis. The abnormal waveforms of umbilical artery and middle cerebral artery were also compared with neonatal nursery admission (Figure 1).

\section{DISCUSSION}

The commonest gynecological lesion seen was leiomyoma uteri; a finding that is reflective of its prevalence especially among black women. ${ }^{10}$ This is significant as fibroids are clinically detectable in $25-80 \%$ of reproductive aged women in community based studies. ${ }^{10}$ The common symptoms seen were prolonged and heavy menstrual bleeding, pelvic pain that was not cyclical, and dyspareunia. Two of the women presented with recurrent early miscarriages, 12 were aware of an enlarging abdominal mass and subfertility, in all twelve cases ultrasonographic studies (which some authors consider to be the gold standard for diagnosis) identified submucus fibroids in the uteri of these women. ${ }^{11}$ These symptoms have been highlighted in other studies. ${ }^{12,13}$ Negro women are reported to have a higher incidence of uterine fibroids at any age as well as more severe symptoms. ${ }^{14,15}$

A study in Enugu gave an incidence of $25.9 \%$, while a different study in Bayelsa reported an incidence of 29.3\%. ${ }^{16,17}$ Much higher incidences have been reported such as $70-80 \%$ in those approaching 50 years. ${ }^{18}$ It is clearly a very common non-malignant tumor of the genital tract as reflected even in this study. Fibroids are a leading cause for gynecological consultation and may affect obstetrical outcomes. ${ }^{19}$ Most fibroids are known to be asymptomatic. ${ }^{11}$

The age range affected most in this study tallies with the ages reported in other studies that show that symptomatic fibroids are common among women within the reproductive age bracket and in many cases there is a need for therapeutic intervention in these women including hysterectomy. ${ }^{20}$

Cervicitis was linked to infections with Neisseria gonorrhoeae, Chlamydia trachomatis and human papillomavirus even though in over half of the cases the exact etiology was unidentified. Broad spectrum antibiotics may be beneficial to some but many may not benefit from such therapy. ${ }^{21}$ The most common presentation was postcoital bleeding and attempts were made to exclude other differentials. Uterovaginal prolapsed which maybe congenital or acquired was associated with multiparity, age and the postmenopausal 
state. Abortions, these were confirmed using product of conception; may either occur spontaneously or be induced. The predominant symptom was vaginal bleeding and abdominal pain. Induced abortions were in the minority compred to spontaneous abortions. This may however not reflect the true rates of induced abortions in the larger society as the cases seen in tertiary centers tend to be the ones with post-abortion complications; one mortality was seen in a case that had become complicated by sepsis. A study in south west Nigeria among women who had undergone one or more induced abortion, only $21.5 \%$ used any form of contraception at first intercourse after the procedure. ${ }^{22}$ The bulk of the abortions in our study were spontaneous abortions mostly in early pregnancy (first trimester). The cases of cervical cysts and polyps that were seen in the study present mainly with abnormal uterine bleeding.

Table 1. Histopathology, frequency, mean age and SD of benign gynecological lesions.

\begin{tabular}{|c|c|c|c|c|}
\hline & Number & Percent & $\begin{array}{l}\text { Mean } \\
\text { age }\end{array}$ & SD \\
\hline Total Sample & 265 & 100 & & \\
\hline \multicolumn{5}{|l|}{$\begin{array}{l}\text { Diagnostics } \\
\text { subsets }\end{array}$} \\
\hline Benign lesions & 265 & 100 & & \\
\hline $\begin{array}{l}\text { Uterine } \\
\text { leiomyomas }\end{array}$ & 120 & 45.3 & 35.7 & 10.3 \\
\hline Cervictis & 32 & 12.1 & 44.9 & 10.6 \\
\hline $\begin{array}{l}\text { Uterovaginal } \\
\text { prolapse }\end{array}$ & 22 & 8.3 & 59.2 & 6.4 \\
\hline $\begin{array}{l}\text { Products of } \\
\text { conation }\end{array}$ & 20 & $7.6 \%$ & 29.6 & 7.4 \\
\hline $\begin{array}{l}\text { Cervical polyps } \\
\text { and cysts }\end{array}$ & 11 & 4.2 & 30.8 & 9.8 \\
\hline $\begin{array}{l}\text { Adenomyosis } \\
\text { and } \\
\text { endometriosis }\end{array}$ & 4 & 1.5 & 37.2 & 4.7 \\
\hline $\begin{array}{l}\text { Serous } \\
\text { cystandenoma }\end{array}$ & 9 & 3.4 & 44.1 & 10.8 \\
\hline Cystic Teratoma & 8 & 3.0 & 26.2 & 6.9 \\
\hline $\begin{array}{l}\text { Simple ovarian } \\
\text { cyst }\end{array}$ & 8 & 3.0 & 25.3 & 10.7 \\
\hline $\begin{array}{l}\text { Endometrial } \\
\text { hyperplasia }\end{array}$ & 7 & 2.6 & 38.1 & 7.8 \\
\hline Ovarian thecoma & 7 & 2.6 & 40.8 & 10.3 \\
\hline $\begin{array}{l}\text { Corpus luteum } \\
\text { cyst }\end{array}$ & 7 & 2.6 & 25.5 & 7.2 \\
\hline Fibroma & 2 & 0.6 & 40.0 & 5.0 \\
\hline Nabothian cyst & 3 & 1.1 & 48.2 & 4.5 \\
\hline $\begin{array}{l}\text { Ectopic } \\
\text { pregnancy }\end{array}$ & 3 & 1.1 & 27.1 & 2.8 \\
\hline Hydrosalpinx & 1 & 0.4 & 38 & - \\
\hline Bartholin's cyst & 1 & 0.4 & 42 & - \\
\hline
\end{tabular}

Adenomyosis and endometriosis were both associated infertility in all the cases seen. Infertile women are 6 to 8 times more likely to have endometriosis than fertile women. ${ }^{23}$ Chronic pelvic pain was seen in one of the cases of endometriosis. Ectopic gestations are most commonly tubal, all were tubal pregnancies in the study and all the affected women had total salpingectomy as the surgical intervention/treatment modality. All the cases had ruptured prior to presentation, with history of preceding mild vaginal bleeding, abdominal pain and dizziness. Other benign lesions included cystic teratomas; here the red flag was abnormal uterine bleeding. Endometrial hyperplasia was accompanied with complaints of menstrual dysfunction. Patients with ovarian thecomas complained of abdominal discomfort and the lesions were discovered sonographically. Only 2 patients with thecomas complained of abnormal uterine bleeding which is a commonly encountered clinical feature of this condition. ${ }^{24}$ Thecomas are rare sex-cord stromal ovarian tumors, they account for roughly $0.5 \%$ $1 \%$ of primary ovarian lesions. ${ }^{24,25}$ Thecomas are frequently interspersed with fiber components (then called 'fibrothecomas'), thecomas and fibrothecomas are now considered to originate from the ovarian medulla, with a different etiology from fibromas, which originate from the cortex. ${ }^{25}$

Corpus luteum cysts were associated with abdominal pain. Simple ovarian cysts were reported histopathological in women who had recurrent abdominal pain and unequivocal ultrasound findings. One patient with ovarian fibroma complained of severe pelvic pain while the others were asymptomatic. Ovarian fibromas are usually asymptomatic but severe pain due to torsion has been documented as well as its association with Meig's syndrome. ${ }^{26}$ Direct contrast enhanced MRI can distinguish ovarian fibromas from uterine fibroids when sonography fails to reveal the origin of a pelvic mass. ${ }^{26}$ Unfortunately the cost of MRIs limits their use in our resource limited environment. Nabothian cysts seen were encountered following routine pelvic examination, they are known to be asymptomatic. ${ }^{27}$ Bartholin's cyst was seen in a 42 year old female who had noticed its insidious increase in size over a 2 year period; she was otherwise asymptomatic. The Bartholin's gland cysts and abscesses happen to be one of the most common vulva cyst or abscesses in gynecological practice and symptomatic cases give significant discomfort to sufferers. ${ }^{28}$ Hydrosalpinx was diagnosed in a patient with subfertility and was visualized sonographically, she was 38 years and desired IVF, salpingectomy was then performed to improve her chances of conception. ${ }^{29}$

\section{CONCLUSION}

Of the specimens analyzed uterine fibroids were the commonest benign lesion for which women underwent gynecological surgery. The majority of cases revealed an overlap in clinical features with very few atypical cases across the entire disease spectrum. It can be said without equivocation that histopathology plays a crucial role in the study of gynecological diseases. 
Funding: No funding sources

Conflict of interest: None declared

Ethical approval: The study was approved by the Institutional Ethics Committee

\section{REFERENCES}

1. Anibue UU, Onyeka TC. Ethical, socioeconomic, and cultural considerations in gynecologic cancer care in developing countries. Int $\mathrm{J}$ Palliative Care. 2014;2014:141627.

2. Buyalos RP, Agarwal SK. Endometriosis-associated infertility. Curr Opinion Obstet Gynecol. 2000;12(5):377-381.

3. Bulletti C, Coccia ME, Battistoni S, Borini A. Endometriosis and infertility. J Assisted Reprod Genetics. 2010;27(8):441-7.

4. Breijer MC, Timmermans A, vanDoorn HC, Mol BWJ, Opmeer BC. Diagnostic strategies for postmenopausal bleeding. Obstet Gynecol Int. 2010;2010:850812

5. Lee K, Wright SM, Wolfe L (2016). The clinically excellent primary care physician: examples from the published literature. BMC Fam Pract. 2016;17:169.

6. Gilks CF, Crowley S, Ekpini R, Gove S, Perriens J, Souteyrand Y. The WHO public-health approach to antiretroviral treatment against HIV in resource-limited settings. Lancet. 2016;368(9534):505-10.

7. Attunueci CA, Ball HG, Zweizig SL, Chen AH. Differences in symptoms between patients with benign and malignant ovarian neoplasms. Am $\mathrm{J}$ Obstet Gynecol. 2004;190:1435-7.

8. Crawford JM. Original research in pathology: judgment, or evidence-based medicine? Lab Investigation. 2007;87:104-114.

9. Vinh-Hung V, Bourgain C, Vlastos G, Cserni G, De Ridder M, Storme $G$ et al. Prognostic value of histopathology and trends in cervical cancer: a SEER population study. BMC Cancer. 2007;7:164.

10. Carlson KJ, Nichols DH, Schiff I. Indications for hysterectomy. N Engl J Med. 1993;28:856-860.

11. Khan AT, Shehmar M, Gupta JK. Uterine fibroids: current perspectives. Int J Womens Health. 2014;6: 95114.

12. Zimmermann A, Bernuit D, Gerlinger C, Schaefers M, Gepper K. Prevalence, symptoms and management of uterine fibroids: an international internet-based survey of 21,746 women. BMC Womens Health. 2012;12:6.

13. Vilos JA, Allaire C, Laberge P, Leyland N. The Management of Uterine Leiomyomas. J Obstet Gynecol Ca. 2014;37(2):157-178.

14. Kjerulff KH, Langenberg P, Seidman JD, Stolley PD, Guzinski GM. Uterine leiomyomas: Racial differences in severity, symptoms and age at diagnosis. J Reprod Med Obsterician Gynecologist. 1996;41(7):483-90.

15. Stewart EA, Nicholson WK, Bradley L, Borah BJ. The Burden of Uterine Fibroids for African-American Women: Results of a National Survey. J Womens Health. 2013;22(10):807-16.
16. Ozumba BC, Nzegwu MA, Anyikam A. Histological patterns of gynecological lesions in Enugu, Nigeria: a five year review from January $1^{\text {st }} 2000$ to December $31^{\text {st }}$ 2004. Adv Biores. 2011;2(2):132-6.

17. Ekine AA, Lawani LO, Iyoke CA, Ibrahim IA. Review of the clinical presentation of uterine fibroid and the effect of therapeutic intervention on fertility. Am J Clin Med R. 2015;3(1):9-13.

18. Baird DD, Dunson DB, Hill MC, Cousins D, Schectman JM. High Cumulative incidence of uterine leiomyoma in black and white women: ultrasound evidence. Am J Obstet Gynecol. 2003;188:100-7.

19. Ouyang DW, Economy KE, Norwitz ER. Obstetric complications of fibroids. Obstet Gynecol North Am. 2006;33:153-69.

20. Da La Cruz, Buchanan EM. Uterine Fibroids: Diagnosis and treatment. Am Fam Physician. 2017;95(2):100-7.

21. Taylor SN, Lensing S, Schwebke J, Lillis R, Mena LA, Nelson AL et al. Prevalence and Treatment Outcome of Cervicitis of Unknown Etiology. Sex Transm Dis. 2013;40(5):10.

22. Lamina MA. Prevalence of abortion and contraceptive practice among women seeking repeat induced abortion in Western Nigeria. J Pregnancy. 2015;2015.

23. Verkauf BS. The incidence, symptoms, and signs of endometriosis in fertile and infertile women. J Fla Med Assoc. 1987;74(9):671-5.

24. Kulkarni YS, Kakade AS, Singh BA. A rare case of ovarian thecoma in a postmenopausal women. Int $\mathbf{J}$ Reprod Contracept Obstet Gynecol. 2014;3(1):242-4.

25. Li X, Zhang W, Zhu G, Sun C, Liu Q, Shen Y. Imaging features and pathologic characteristics of ovarian thecoma. J Comp Assist Tomograph 2012;36(1):46-53.

26. Thomassin-Naggara I, Darai E, Nassar-Slaba J, Cortez A, Marsault C. Value of dynamic enhance Magnetic resonance Imaging in distinguishing ovarian fibroma and subserosal uterine fibroid. J Comp Assist Tomograph. 2007;31(2):236-24.

27. Kennedy S, Bergqvist A, Chapro C, D'Hooghe, Dunselman G, Greb R et al. ESHRE guideline for the diagnosis and treatment of endometriosis. Hum Reprod. 2005;20(10):2698-2704.

28. Pundir J, Auld BJ. A review of the management of diseases of the Bartholin's gland. J Obstet Gynecol. 2008;28(2):161-5.

29. D'Arpe S, Franceschetti S, Caccetta J, Pietrangeli D, Muzii L, Panica PB. Management of Hydrosalpinx before IVF: a literature review. J Obstet Gynecol. 2015;35(6):547-60.

Cite this article as: Uzoma OI, Ejikem EC. Clinicohistopahological patterns of benign gynecological lesions at a tertiary hospital in Eastern Nigeria: a 5 year review. Int J Reprod Contracept Obstet Gynecol 2017;6:2690-3. 